\title{
Overcoming Isolation in Distance Learning: Building a Learning Community through Time and Space
}

Nicholas Croft, Alice Dalton \& Marcus Grant: University of the West of England, Bristol, UK

\begin{abstract}
The rise in popularity of distance education programmes, taught through web-based media, belies the difficulty in preparing, delivering and studying on such programmes. Preparing and providing quality material and a rich learning experience are key challenges. The physical and temporal separation of tutor and student, and between students themselves, can lead to feelings of isolation. The lack of interaction and discussion between students on non-cohort based courses lessens the richness of the learning experience and omits a significant element of the constructivist approach to learning. In order to provide maximum flexibility for students to study at a time, pace and in a subject issue of their choosing, the University of the West of England's (UWE) MA Spatial Planning programme is delivered entirely online at a distance and asynchronously.

This research investigates this pedagogic problem through examining the experiences of distance learning students at UWE, exploring issues and barriers to collaborative study, and exploring student isolation. Recommendations are generated for building a learning community on a non-cohort asynchronous programme of study. These include: providing service level agreements to clarify expectations; designating 'staging points' to encourage and motivate; developing student generated content as footprints 'buried' in the material; humanising the material; and introducing mechanisms to provide students with their peers' thoughts/views on course material.
\end{abstract}

Keywords: Distance Learning, Isolation, Student Community, E-learning, Non-cohort 
N. Croft, A. Dalton \& M. Grant: Overcoming Isolation in Distance Learning: Building a Learning Community through Time and Space

\section{Introduction}

This paper discusses distance learning in higher education and its use as a means to help address skills shortages in the built environment sector. It examines and extends empirical research regarding the student learning experience on distance learning programmes, namely those where the studying is wholly at a distance with no face-toface contact with staff or students. Barriers and challenges to the learning experience identified in the literature, including isolation, are examined and expanded through examining student experiences on four asynchronous programmes at the University of the West of England (UWE). Potential solutions to overcome these and create a successful virtual learning community are proposed and evaluated, recognising that any such improvements will need to be reconciled with an identified primary benefit of studying at a distance: that of flexibility, in terms of time, convenience and location.

This first section of this paper provides an overview of distance learning in higher education: it discusses skills and learning in built environment professions; what is meant by the student learning experience; and finally the challenges and potential solutions to overcome barriers in distance learning. This section concludes with a response in terms of the research objectives for an empirical enquiry. The second section provides a description of the research methodology used for this enquiry. A three-stage approach was used to evaluate the student learning experience on distance learning courses at UWE; identifying barriers and challenges to learning, and exploring potential solutions to overcome these. The three stages included exploratory interviews with students, a participatory workshop with staff and students and a student survey to evaluate ideas proposed in the workshop. The third section presents the findings from this empirical research. A final fourth section presents the conclusions along with some recommendations.

\section{Distance learning in higher education}

Distance learning can be defined as a process whereby tutor and student are separated spatially and by time (Liu, 2008) and it relates to programmes of study which are delivered entirely off-campus. Prior to the use of the Internet, two approaches to distance learning were developed and used alone or by combining the two. One is a paper-reliant approach, where the student receives a package of material through the post, completes the package and returns it via the post and then receives feedback. The other approach uses instructional videos or television programmes, when the student views a pre-recorded lecture usually enhanced with documentary style material and visual aids; completes the task, returns it via the post and then receives feedback (Nipper, 1989). More recently distance learning is being delivered through placing course material online, using e-mail and social networking media as support.

Lake (1999, p.14) notes that 'technological change has enabled the materials of education to be dispersed economically in new ways with fewer temporal and spatial constraints'. Students therefore no longer need to attend regular lectures delivered in 
N. Croft, A. Dalton \& M. Grant: Overcoming Isolation in Distance Learning: Building a Learning Community through Time and Space

theatres alongside other students at a predetermined time and location, and they encounter a different learning environment. Universities have embraced this opportunity, given its potential for increasing student numbers without having to accommodate them physically. Distance learning is thus becoming an increasingly popular way to deliver higher education, which is illustrated by the range of distance learning courses provided in higher education establishments (Liu et al., 2006).

The term 'distance learning' has been used in the literature to incorporate programmes that are based online but which also include face-to-face contact sessions. Such programmes are referred to in this paper as 'blended learning' programmes. Education delivered at a distance is also variably referred to as 'e-learning', 'on-line learning' and 'distance education' (Liu, 2008). This study relates solely to distance learning whereby the courses are delivered remote from the university (and any hired off-site facility) and whose students and staff never meet face-to face. We also focussed on courses related to the built environment, albeit that reference is made to examples from other fields.

\section{Skills and learning in built environment professions}

According to an Academy for Sustainable Communities report in 2007, recruiting suitably qualified personnel is a problem in many built environment professions, including planning, architecture, regeneration and sustainability sectors. The current crisis in recruiting planners, and in 'up-skilling' existing staff, has been widely acknowledged (Royal Town Planning Institute, 2005; Audit Commission, 2006; Asset Skills, 2006; Croft, 2007). Professionals in these sectors may be required to undertake continuing professional development (CPD) as part of their role. CPD is defined by the Royal Town Planning Institute (RTPI) as: 'the means by which members of professional associations maintain, improve and broaden their knowledge and skills and develop the personal qualities required in their professional lives' (RTPI, 2007).

Indeed, the Department for Communities and Local Government (CLG) see CPD as an effective way of introducing professionals to the changes in the planning system in England, following the introduction of the Planning and Compensation Act 2004, the Planning Act 2008 and more recently the proposed changes to the planning system following the change of UK government in 2010.

Maintaining appropriate levels of CPD (which for RTPI members equates to fifty hours in any given two year period) however can be difficult. This is especially so given that the learner is likely to be 'mature' (over 21 years of age according to Directgov (2009)), with family commitments, and in full time employment. Distance learning programmes are being provided to address the demand for flexible training that addresses the realities of work/life pressures and this is a key benefit of distance learning for professionals (Wall et al., 2006). Distance learning methods of study are therefore potentially attractive to those who face significant work/life pressures and for whom regular attendance at a higher education institution for a traditional form of delivery is 
N. Croft, A. Dalton \& M. Grant: Overcoming Isolation in Distance Learning: Building a Learning Community through Time and Space

neither practicable nor desirable (Gammie et al., 2002). Distance learning therefore has the potential to address the skills shortage in a range of sectors, through providing targeted flexible training.

Benefits of distance learning can be identified for both the students and the institution. For the student these include the opening up of new opportunities for those who were previously excluded or disadvantaged due to geographic and social issues: location (rural or isolated); transport; family/caring needs; and time constraints can also be overcome through flexible delivery (Lake, 1999). Gaining certified qualifications can be a route to improved job prospects (Lake, 1999) and potentially increased job satisfaction. The advantages for higher education establishments in providing CPD consist of providing closer links with industry and professional bodies; potential funding for research; and cascading information down into undergraduate programmes to keep them up-to-date with the latest industry position (Thomas, 1995). However, these benefits can potentially conflict with the student experience.

\section{The student learning experience}

Many different factors contribute to the student learning experience. These vary according to the individual circumstances of each student, including: their learning style; personal situation; ICT skills, confidence and attitude (Webster and Hackley, 1997) and familiarity (Mason and Bacsich, 1998); background subject knowledge; motivation; effectiveness of teaching; communication with staff and between students; time to study; access to ICT support; and group working encounters (Alexander, 2001). A good learning experience, according to Eastmond and Ziegahn (1995, p.59) is one where a student can, '...master new knowledge and skills, critically examine assumptions and beliefs, and engage in an invigorating, collaborative quest for wisdom and personal, holistic development'.

Understanding how the student learns is crucial for understanding how distance learning courses should be delivered. Weller (2002) states that constructivism is probably the principal pedagogical approach used in designing online courses. This approach is based on students actively constructing their own knowledge, based on personal experience (Quilter and Weber, 2004; Weller, 2002; Gulati, 2008). A 'resource based' approach to teaching requires students to consult and engage with a wide range of materials and sources independently of the tutor, providing the freedom to explore information that best suits their learning style (Weller, 2002). The Internet allows access to extensive data and literature that students can be encouraged to explore. It is noted that although technology can enrich the experience (Carswell et al., 2000), the use of technology in itself does not necessarily make learning interesting or engaging (Cleveland and Bailey, 1994) and it does not necessarily ensure academic success (Wegner et al., 1999). Further requirements of constructivism include experiential learning (Kolb, 1984), interaction with other students, colleagues and academic staff (So and Brush, 2008; Stacey, 1999) and collaborative learning (So and Brush, 2008). 
N. Croft, A. Dalton \& M. Grant: Overcoming Isolation in Distance Learning: Building a Learning Community through Time and Space

This has been used effectively in traditional learning, but 'its effectiveness in distance education contexts has yet to be firmly demonstrated' (Bernard et al., 2000, p.7). Bonwell and Eison (1991) note that for students to learn they need to experience a more 'active learning' environment, where they engage in reflective interaction with other students. According to Bernard et al. (2000), for collaborative learning to be successful a 'learning community' needs to be created so that the student feels part of a wider group. If the Internet is acknowledged and developed as a communication tool, the 'collaborative learning' mode can be promoted (Weller, 2002), so embodying the social aspect of learning by encouraging students to interact with one another. This is a significant opportunity, but not one without challenges for those designing and delivering distance learning programmes.

\section{Challenges for distance learning}

The delivery of course programmes is a significant challenge for distance learning tutors. The traditional lecture comprises the most common method of providing higher education learners with information (Fry et al., 2003); however, this does not generally translate well into online learning (Weller, 2002). Placing material on the Internet and merely providing materials for tuition is not sufficient for learning: better use must be made of technology (Chee, 2002). In addition, the needs of the learner must be addressed otherwise online learning will not produce successful results (Willis, 1994; Hamid, 2002). The tutor is responsible for 'preparing the instructional environment' (Wegner et al., 1999, p.104) which guides student learning; however the student may experience difficulties in undertaking their own knowledge construction (Alexander, 2001). Providing online activities has particular challenges, including difficulty of encouraging participation (Gibson et al., 2001), anxiety of students (Hughes and Daykin, 2002), difficulty of creating successful critical/analytical dialogue (Hughes and Daykin, 2002), potential for mistaken beliefs to be generated and shared (Weller, 2002), difficulty of tutor facilitation of online debate (Hughes and Daykin, 2002) and ability of the tutor to answer queries promptly.

According to Connolly et al. (2005, p.66), 'developing appropriate materials is a major challenge' for distance learning. Substantial time is required for preparing and delivering material (Willis, 1994), and this requires continual updates and maintenance. Material must not infringe copyright; material must be up-to-date yet it is 'costly to make constant changes'; and the material must be in an appropriate format (Willis, 1994, p.66). On the other hand, the availability of material through the Internet provides learners with flexibility and a wide range of information sources and different media. This can, however, present difficulties for tutors in terms of addressing the tension between rigid structure and responsive flexibility in terms of designing online material that meets learners' changing needs (Stodel et al., 2006).

The availability of distance learning has led to a greater diversity in student type, which is a key challenge for delivering online programmes (Connolly et al., 2005; Lorenzetti, 2005; and Lake, 1999), as students in higher education use a wide variety of learning 
N. Croft, A. Dalton \& M. Grant: Overcoming Isolation in Distance Learning: Building a Learning Community through Time and Space

styles. Lynch (2004) suggests that aural learners perform well in traditional lectures whereas those with a visual learning style would favour the Internet. However, much online teaching may 'fall into the trap of 'one-size-fits-all' approach' (Wall et al., 2006, p.1). The skill of course design for teaching adults is therefore in 'finding alternative ways of conveying information and ideas' (Rogers, 2001, p.22). This is of particular concern in a distance learning environment where there is potential for a student's intellectual isolation through the lack of a cohort to progress ideas.

Motivation is the most important factor for effective learning according to Rogers (2001). Motivation is therefore important for all students, whether studying on traditional face-to-face courses or at a distance (Rovai et al., 2007, and Whiting et al., 2008). Traditional students are more likely to be extrinsically (externally) motivated whereas distance learners tend to be intrinsically (independently) motivated (Whiting et al., 2008). Our study focuses on the latter who, unlike traditional full time students, are studying whilst in related employment and are likely to be motivated from the outset by having 'more interest, confidence... and conceptual understanding' (Whiting et al., 2008, p.288). Additionally they may recognise professional rewards from their education (increased salary, more responsibility, better job prospects and so forth) (Rogers, 2001) or fear of a penalty (having to repay course fees to their employer) which are extrinsically motivating.

Studying alone can be time-consuming and consequently requires heightened levels of motivation. Self-discipline, careful planning (Liu, 2008) and time management (Alexander, 2001) are skills that need to be embedded into the course. Whilst this can also be true of traditionally taught courses, physically attending lectures demands accountability from students (Dickey, 2004), which in turn may assist motivation through social engagement with peers: distance learning does not have this benefit where the autonomy of the student necessitates higher levels of intrinsic motivation. Whiting et al. (2008, p.293) note that the design of distance learning materials can be specifically tailored to encourage intrinsic motivation in students, by providing 'stimulating courses... and challenging tasks'. Such an online element could also be incorporated into traditional classroom teaching to encourage more independent thinking (Whiting et al., 2008).

The technology (ICT) used to facilitate distance learning requires an increased level of learning discipline and motivation, particularly as using new technology at the same time as engaging with new subject material can be difficult. Students can experience ICT related problems including: incompatible software; incorrect hardware; inability to use software correctly; and computer viruses. These can lead to frustration and anxiety (Salmon, 2000; Connolly et al., 2005). Belief in their own abilities influences students' willingness to use technology (Compeau and Higgins, 1995), and their success at doing so (Webster and Hackley, 1997). Success is also more likely if students feel the outcomes of their efforts are important (Compeau and Higgins, 1995, p.191). Hughes 
N. Croft, A. Dalton \& M. Grant: Overcoming Isolation in Distance Learning: Building a Learning Community through Time and Space

and Daykin (2002) found that once the students had gained a feeling for the 'new' experience, their early fears regarding ICT subsided.

Students beginning distance learning programmes may feel uneasy about what to expect or the standard of work required. This anxiety may adversely affect a student's ability to learn (Rogers, 2001). Students undertaking a formal education process expect their learning to be structured (Gulati, 2008). Without physical attendance students cannot observe the input being given by their peers or understand what constitutes an appropriate amount of study (Lake, 1999). Therefore, 'instilling appropriate expectations among all participants' is a key element to success (Carswell et al., 2000, p.45). Student expectations regarding online communications may be high, yet issues of time-lag between emails, timeliness of contact and availability of participant may limit levels of discussion and support (Lake, 1999).

Research by The Higher Education Academy (Park, 2008, p.16) found that $22 \%$ of distance learning students mentioned 'the risk of feeling isolated' as a challenge, reflecting findings that personal interaction is important for student learning (Ipsos MORI, 2007). Psychological isolation may result from the physical and temporal isolation experienced by learning at a distance (Lake, 1999). This issue is also raised by Wegner et al. (1999); Barrett and Lally (2000); Hartley et al. (2001); Rovai (2001); Dickey (2004); Lorenzetti (2005); and Stodel et al. (2006). Isolation can be understood as being in terms of such dimensions as time (concurrent study); space (geographic dispersal); social (awareness of others), intellectual/experience (academic ability and life experiences); profession (subject related expertise); ICT knowledge; sensory (ability to see/feel/hear peers); cultural; and subject (if anyone else is studying the same topic). Reassurance and peer contact (Venter, 2003) as well as appropriate support (Lake, 1999) is required to overcome this isolation, yet this is a challenge without face-to-face contact. Students' individual learning style and motivation for studying may affect their willingness and need to interact with others (Liu, 2008), and therefore their experiences of isolation. Encouraging student participation in online discussions and therefore interaction with peers may help to reduce isolation, however making this compulsory may not be effective (Gulati, 2008) and discussion may not always be appropriate for learning (Hughes and Daykin, 2002).

Distance learning courses experience high drop-out rates for many of the reasons identified in the sections above and in particular, isolation seems to be a significant contributory factor (Lake, 1999; and Hartley et al., 2001). If appropriate support is not provided for students, student withdrawal from the course may be more likely (Gammie et al., 2002). Notwithstanding the impact on students and their peers, withdrawal from courses has 'economic and social concerns for the university' (Gammie et al., 2002, p.16) and is something that needs to be considered.

A particular distance learning challenge, that is perhaps unique to the University of the West of England, Bristol (UWE), concerns a specific mode of distance learning: the non-cohort course. Sharing ideas helps students to improve their learning and 
N. Croft, A. Dalton \& M. Grant: Overcoming Isolation in Distance Learning: Building a Learning Community through Time and Space

understanding and is a necessary part of an individual's cognitive development (Vygotsky, 1978). However, in a non-cohort course there is an absence of students who are at the same point in the course, removing the opportunity for direct communication with a relevant peer group. Technology therefore must overcome a temporal as well as a spatial distance. To date, there has been no research on isolation in respect of non-cohort distance learning. Our research has sought to address this and to consider options for overcoming feelings of isolation.

\section{Learning community solutions for distance learning}

Various methods can be used in distance-learning courses to 'reduce feelings of alienation' (Dickey, 2004, p.290). The notion of building an online community for learning has been explored, suggesting that this can overcome the absence of physical contact between students (Liu, 2008) and improve teaching (Thomas, 2002) by allowing for structured interaction (Garrison et al., 2000) or as a peer support network (Hartley et al., 2001). A virtual cohort may therefore be created. In order to facilitate the creation of an online community, a range of solutions has been applied. Blogs have been shown to create a sense of community among students which may reduce psychological isolation (Dickey, 2004). These are preferable to other web-based tools such as 'Blackboard' (a proprietary dedicated teaching and virtual learning environment), which may be confusing (Dickey, 2004). Online discussion forums may result in 'increased student engagement, critical analysis and reflection, and the social construction of knowledge' according to a review by Thomas (2002, p.352), provided the expected outcomes are explicitly stated (Stodel et al., 2006). However, issues of asynchronicity, the 'artificial' structure of the conversation and the uneasy nature of written communication continue to present problems (Thomas, 2002). Other issues that can affect the nature of online communications include the permanence of postings; the creation of social relationships between people; the perceived usefulness of the activity; the fluency of online dialogue; students' desire not to offend others with their comments (Stodel et al., 2006). In addition, requiring students to communicate with each other precludes learners from learning alone where desired (Gulati, 2008).

The use of personal tutors, online/telephone assistance, work place mentors, peer learning, group induction sessions, study skills workshops and access to local libraries have been suggested by Talbot (2007). These mechanisms are used in the Government sponsored e-learning initiative, the Foundation for Government (F4Gov) programme, which is for improving individual and organisational performance in the Civil Service (Talbot, 2007). It is noted that these measures seek to overcome isolation not by technological innovation, but by introducing a degree of personal contact, either between peers, with work colleagues and between students and tutors.

Mentoring can be used as a way of providing advice and guidance to new students starting a particular course. Barrett and Lally (2000, p.7) proposed a 'peer mentoring' approach to overcome isolation through the creation of a 'student community'. Student experiences were recorded on CD ROM and circulated to subsequent cohorts to 
N. Croft, A. Dalton \& M. Grant: Overcoming Isolation in Distance Learning: Building a Learning Community through Time and Space

provide 'supportive voices' for students, which were described as 'interesting and motivating' by students (Barrett and Lally, 2000, p.7). This was advocated by Miller et al.'s (2008) research into nursing practice, suggesting that students need to form two relationships, one with their tutor and then another with their mentor (Miller et al., 2008, p.395).

Tutors must play a significant role in providing advice, support and guidance to distance learning students (Wegner et al., 1999; Lynch, 2004). Creating a sense of belonging and care as part of the relationship between student and tutor is essential (Venter, 2003). Hughes and Daykin (2002) found that distance learning students preferred to contact the module leader, rather than fellow students or a 'frequently asked questions' option on the website. Venter's (2003) concept of 'surrogate teacher' for the tutor to guide and assure students is pertinent. Increased dialogue is necessary in order to reduce perceived distance between student and teacher (Dron, 2006; So and Brush 2008). 'Timely and accessible' tutor feedback on formative work or to gain support/advice is crucial, as the immediacy of tutor response can avoid unresolved issues escalating in the student's mind (Lake, 1999, p.17). This can help to offset difficulties for students before they become a major issue and before they consider that they do not have sufficient support from the university, which is important for maintaining a student's confidence (Lake, 1999). However, student numbers on a course can impact upon the time available to the tutor to provide feedback.

Various measures relating to the material, content and delivery of distance learning courses can be used to help the student learning experience. The standard of the material on the website must be appropriate and sufficiently maintained as it is the principal point of contact with the student. Assignment expectations and requirements need to be explicitly stated online (Lake, 1999). Regular assessment tasks encourage engagement with the material (Rust, 2002, p.154) as will embedded activities throughout the online modules. It may be appropriate to include videoed lectures online to introduce the topic and create a more personalised approach. Collaborative learning and student interaction is facilitated by the design of the distance learning course (Hughes and Daykin, 2002; Alexander, 2001; Liu, 2008), and the tutor has to stipulate that the final mark will reflect that interaction (Liu, 2008).

The intention of identifying solutions is to put in place a strategy for building a learning community to enhance the student experience. Ultimately the intention is that this can be tested on such programmes at the University of the West of England (UWE).

\section{Purpose of the study}

UWE's Planning and Architecture Department has 'long experience of distance learning courses in planning' (UWE, 2009). UWE has designed, built and is delivering online programmes providing both targeted CPD and flexibly delivered Masters level qualifications. Four programmes are studied purely by distance learning (see below), one of which is the MA Spatial Planning, consisting of a series of topics which can be 
N. Croft, A. Dalton \& M. Grant: Overcoming Isolation in Distance Learning: Building a Learning Community through Time and Space

studied in any order and independently. Students register whenever suits their personal circumstances and thereafter study at their own pace: the courses are therefore asynchronous and have no cohort.

The programmes seek to adopt a constructivist approach to learning by encouraging students to use personal experience to provide reflective interpretation, and collaborative learning to form opinion using discussion with work colleagues. The technically defined pedagogic platform used has been termed Flexible Learning in Context (FLIC), where the work programme and associated materials encourage student learning in the context of their organisation. This is achieved by requiring students to undertake specific activities/exercises in which they use examples from their workplace to examine the theories and ideas around best practice identified in the online material. Furthermore, case studies are introduced throughout the material to illustrate approaches used by other professionals, which students are then encouraged to critique with reference to their experience. This makes learning relevant to the work students are engaged in, more interactive and more engaging, encouraging debate and reflection (Bryan, 2003; Bryan et al., 2003; Garnet, 2005).

The MA Spatial Planning is an entirely web-based course where students currently never meet the tutor or other students, and communication is mostly asynchronous. As a consequence of the flexible nature of the course, there is no readily identifiable cohort, which presents additional difficulties in terms of students feeling isolated. The challenge at UWE is therefore to overcome these potential difficulties and deliver programmes that successfully maximise, or enrich, the student learning experience and provide a sense of 'community' to students who do not have a natural course cohort.

The rise in popularity of social networking and other web-based technologies suggests that there may be scope to introduce such mechanisms into the distance learning programmes at UWE in order to overcome students' feelings of isolation. Gaining further knowledge about the experiences of students on distance learning courses, and their perceptions of web-learning environments, will be necessary to advance this debate (Dickey, 2004).

\section{Research aim}

The aim of the paper is to investigate, understand and seek to overcome issues that detract from students' learning experience. It is our belief that the student learning experience could be enhanced if further investigation into the pedagogic problem presented by the e-learning environment, led to the establishment of an effective learning community building strategy.

The research question addressed is: 'How can the student learning experience on a non-campus based programme, where there is no course cohort, be enriched through reducing the potential for isolation?' 
N. Croft, A. Dalton \& M. Grant: Overcoming Isolation in Distance Learning: Building a Learning Community through Time and Space

Three sub-questions are generated from this:

- What are the experiences of students on the four non-cohort built environment distance learning courses at UWE?

- What are the barriers and challenges to improving the learning experience for these students?

- What solutions could be used to overcome these barriers and challenges?

It is acknowledged that methods of delivering online learning must be continuously improved and monitored, especially in response to student concerns. As such, this research has sought to understand what factors contribute to isolation and what measures can be put in place to overcome it.

\section{The Research}

Following a review of the academic, theoretical and policy literature, a three-stage mixed method approach (Bergman, 2008) to the research was adopted, guided by the three research sub-questions. The first stage sought to gather qualitative information about the range of distance learning experiences from a diverse range of distance learning students. This followed a grounded theory approach (Glaser, 1992) to collect information inductively by exploring student experiences rather than testing existing theory. This was analysed to identify key themes regarding student experience, problems with distance learning, and to begin to identify potential solutions to overcoming students' identified barriers to learning, in particular where these related to isolation. The second stage used a creative participatory inquiry technique to generate potential solutions involving both staff and students. The outcomes from this were analysed to inform the design and content of stage three. The third stage sought to elicit reactions to these potential solutions with students on distance learning courses, to understand how they would be received, to improve details of the solutions and to explore the potential implementation.

The population of interest were students who were enrolled on pure distance learning Masters level courses with no cohort at the UWE. This included students who had completed, or were currently studying, for courses for the purpose of a full Masters degree or as CPD. This included a total of 154 students registered on the following programmes:

- MA Spatial Planning (47 students)

- MSc Countryside Conservation and Management (22)

- MA Community Safety and Crime Prevention (41)

- MSc Urban and Rural Regional Regeneration (44) 
N. Croft, A. Dalton \& M. Grant: Overcoming Isolation in Distance Learning: Building a Learning Community through Time and Space

The staff to student ratio on these courses varies due to their asynchronous delivery. Tutors on the MA Spatial Planning programme will often only have one student studying on their topic at any one time and rarely have more than four or five students.

\section{Data protection and ethical review}

Under the Data Protection Act, the information held on students, including contact details, can only be accessed by the university's Student Advisors, unless permission is specifically granted by the student. The Student Advisors contacted the students initially via email, in order to ask students if they would be happy to be involved in the research and for their information to be used. Twenty three students responded positively to this email.

\section{Stage one}

Interviews were conducted with students at UWE for the first stage of research in order to explore their experiences of distance learning. An interview sheet was devised to guide the interviewer through each interview conducted, to cover areas including: the course enrolled on; experience of the course; methods of communication; and interviewee employment situation (Appendix A). By using this semi-structured approach, interviewers ensured that all aspects necessary to answer the research questions were explored. This also allowed comparability of responses, particularly as more than one researcher undertook the interviews. This style of interviewing allows the interviewer to change the order of questions or to add/omit questions when appropriate (Robson, 2002).

Students consenting to their involvement were interviewed over the telephone. Faceto-face interviewing was impractical due to the geographical dispersal of the students enrolled on the distance learning courses, but research suggests that there are no significant differences between face-to-face and telephone interviews (Sturges and Hanrahan, 2004). The interviewers contacted each other after their first interview, which allowed reflection on the interview process and additional guidance. No further amendments were deemed necessary to the interview sheet. The interview sheet was used as a guide and interviewees were probed as appropriate to elaborate on their experiences of being a distance learning student. A total of 19 interviews were conducted by four researchers.

Interviewers made notes on a hard copy of the interview sheet as they progressed through the interview. Each interview lasted between twenty and thirty minutes and was recorded using a digital recorder and telephone coil attached to the telephone handset. The interviews were transcribed by an external transcription organisation (as verbatim, excluding 'ums and ahs') and then checked by the researchers for accuracy. The researchers tasked with carrying out the analysis familiarised themselves with the transcripts by reading through them all and noting any initial thoughts about the findings of the interviews. 
N. Croft, A. Dalton \& M. Grant: Overcoming Isolation in Distance Learning: Building a Learning Community through Time and Space

The data were analysed using a process of thematic analysis (Boyatzis, 1998) in specific qualitative analysis software (NVivo). Codes were assigned to categorise particular pieces of text taken from interview scripts. Theme headings were created using themes arising from the interview sections. Sub-headings were created as appropriate to include aspects such as positive and negative experiences and suggested improvements. This process was repeated several times and the theme headings were refined accordingly. Two different researchers coded the interviews then discussed findings in order to ensure consistency of coding and agreement on the final themes. Following this analysis, the findings from the interviews were written up by categorising responses under the given themes.

\section{Stage two}

The aim of the second stage of research was to develop a series of ideas that would represent potential workable solutions to deficiencies in the student learning environment, particularly in relation to dimensions of isolation. In order to generate solutions to our pedagogical issue in a creative manner, a 'sandpit' participatory research session was convened at UWE, using workshop ideas developed by the Engineering and Physical Sciences Research Council (EPSRC). The EPSRC defined a 'sandpit' workshop as 'a place for adventurous, playful solution construction' in order 'to look at the issues in creative, multidisciplinary ways' (Jones, 2006, p.16). This uses a brainstorming process, allowing for investigation of experiences and exploration of solutions to a particular problem.

The objectives of the workshop were:

- to address the dimensions of isolation experienced by students on distance learning courses at UWE, as identified from a previous stage of empirical research

- to investigate possible and innovative solutions to overcome these dimensions and enhance the learning environment

A total of 19 people (13 staff and six students) attended the event. As part of the creative research stage, invited participants included not only those involved with pedagogic support but also those from product design, IT systems analysis and community computing. Following an introduction to the workshop programme, the session comprised four activities, undertaken as small group work. The four sequential components to the sandpit session were:

A. Understanding and exploring a dimension of isolation: Using a wide range of images on cards provided, participants were first asked to select those images which best depicted components of their allocated dimension of isolation, to attach these images to a prepared wall poster template, adding text in order to make an 'isolation cloud'.

B. Proposing conceptual solutions: Participants were then asked to propose some basic conceptual solutions to overcome the component of isolation they 
N. Croft, A. Dalton \& M. Grant: Overcoming Isolation in Distance Learning: Building a Learning Community through Time and Space

had been working on. They were to capture and communicate their group thinking through again selecting images and adding text as appropriate.

C. Selecting solutions on which to focus: Having found some conceptual solutions, participants were then asked to select three of these as 'big ideas' for further development, exploring mechanisms for implementation.

D. Identifying common threads across the solutions: A plenary activity was held at the end of the session, where each group gave their findings of the three 'big ideas' identified to overcome their allocated dimension of isolation, and commonalities were identified between the groups.

Five dimensions or 'axes' of isolation that affect distance learning students were discussed. These were introduced as: chronological (time delay), communication (alternatives to face-to-face contact), geographical (distance), professional (understanding) and technological (using IT). Participants were invited to discuss each of these axes and were therefore distributed across five topic tables. Each topic table consisted of one anchor person (from the project team) to act as chair. Objects were provided to stimulate the discussion of each dimension of isolation and included photographs, oval sticky notelets, paper, felt pens and Lego. The workshop was facilitated throughout and conducted in a deliberately planned rapid style in a visually rich environment. Images from the event are set out below.

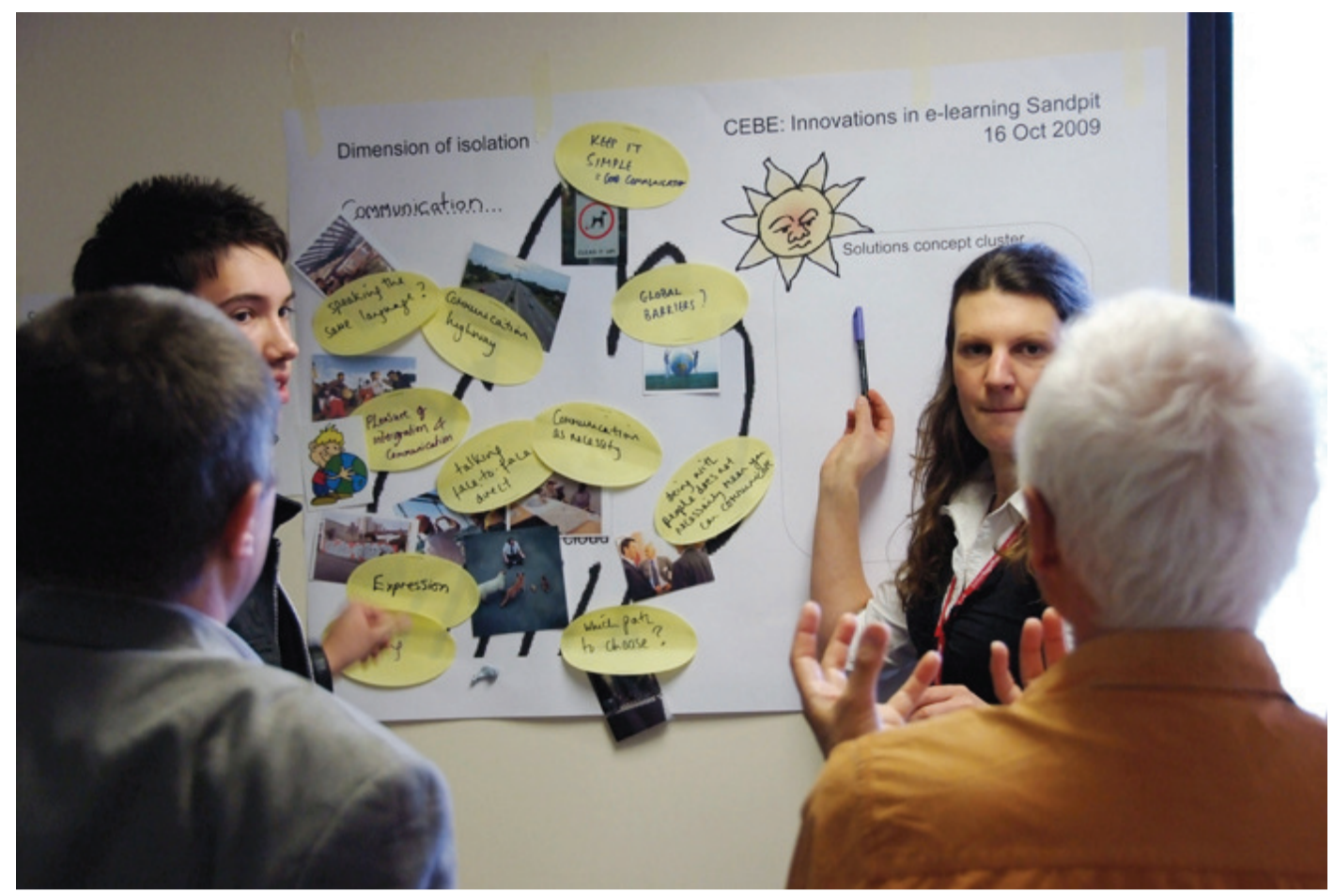

Figure 1 Participants discussing the issues as they complete a wall template 
N. Croft, A. Dalton \& M. Grant: Overcoming Isolation in Distance Learning: Building a Learning Community through Time and Space

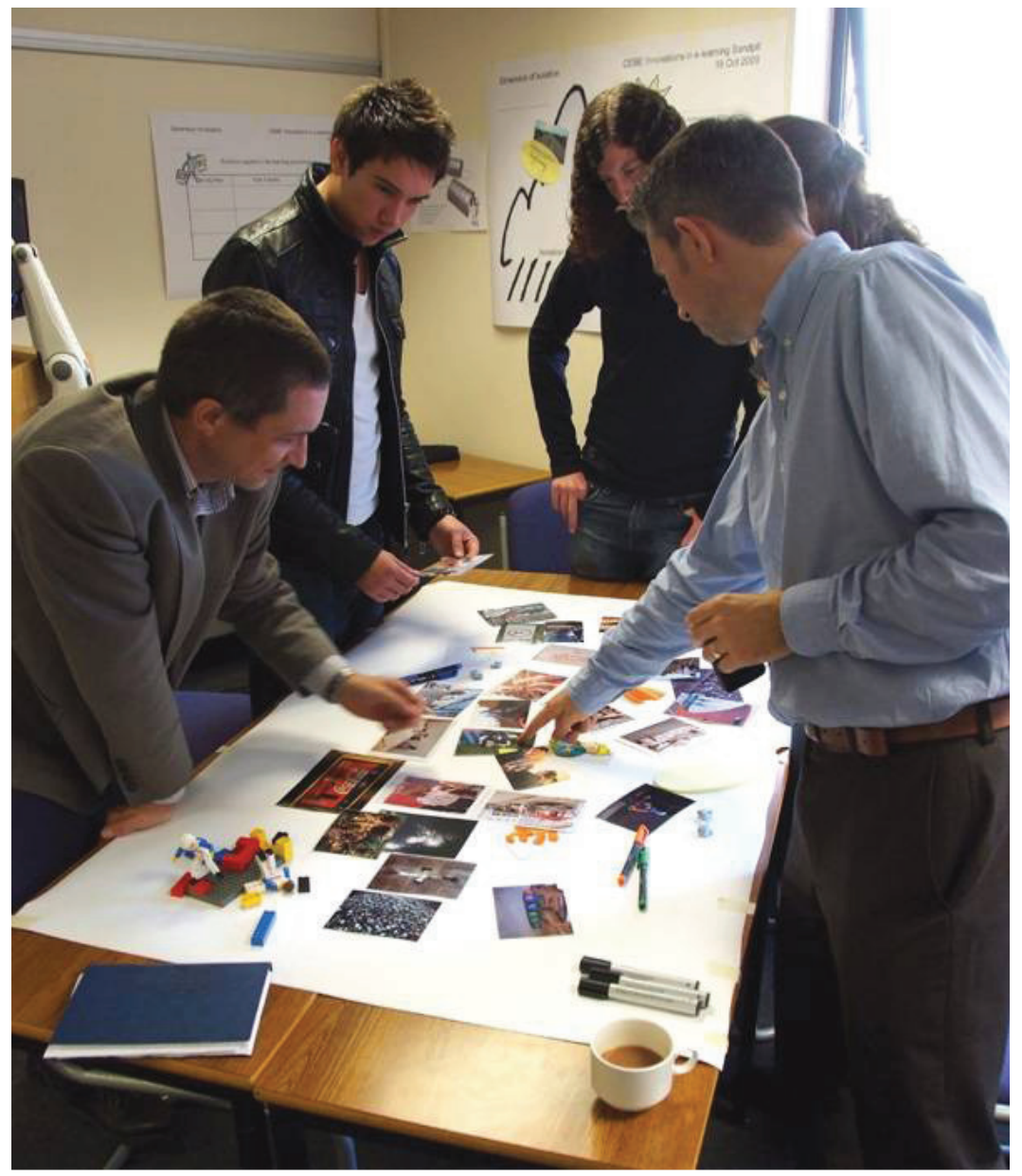

Figure 2 Small group table work, note the image cards

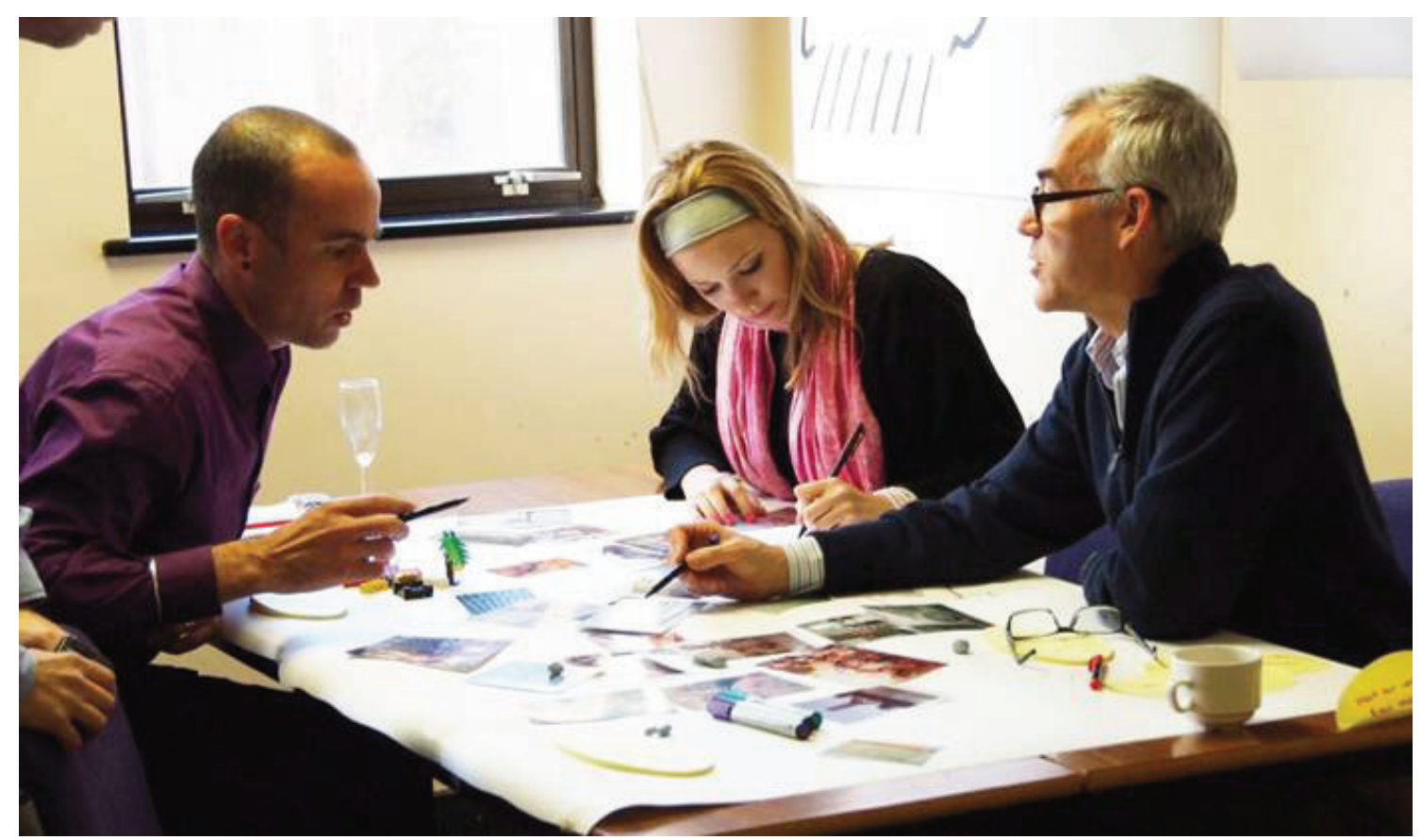

Figure 3 Small group table work 
N. Croft, A. Dalton \& M. Grant: Overcoming Isolation in Distance Learning: Building a Learning Community through Time and Space

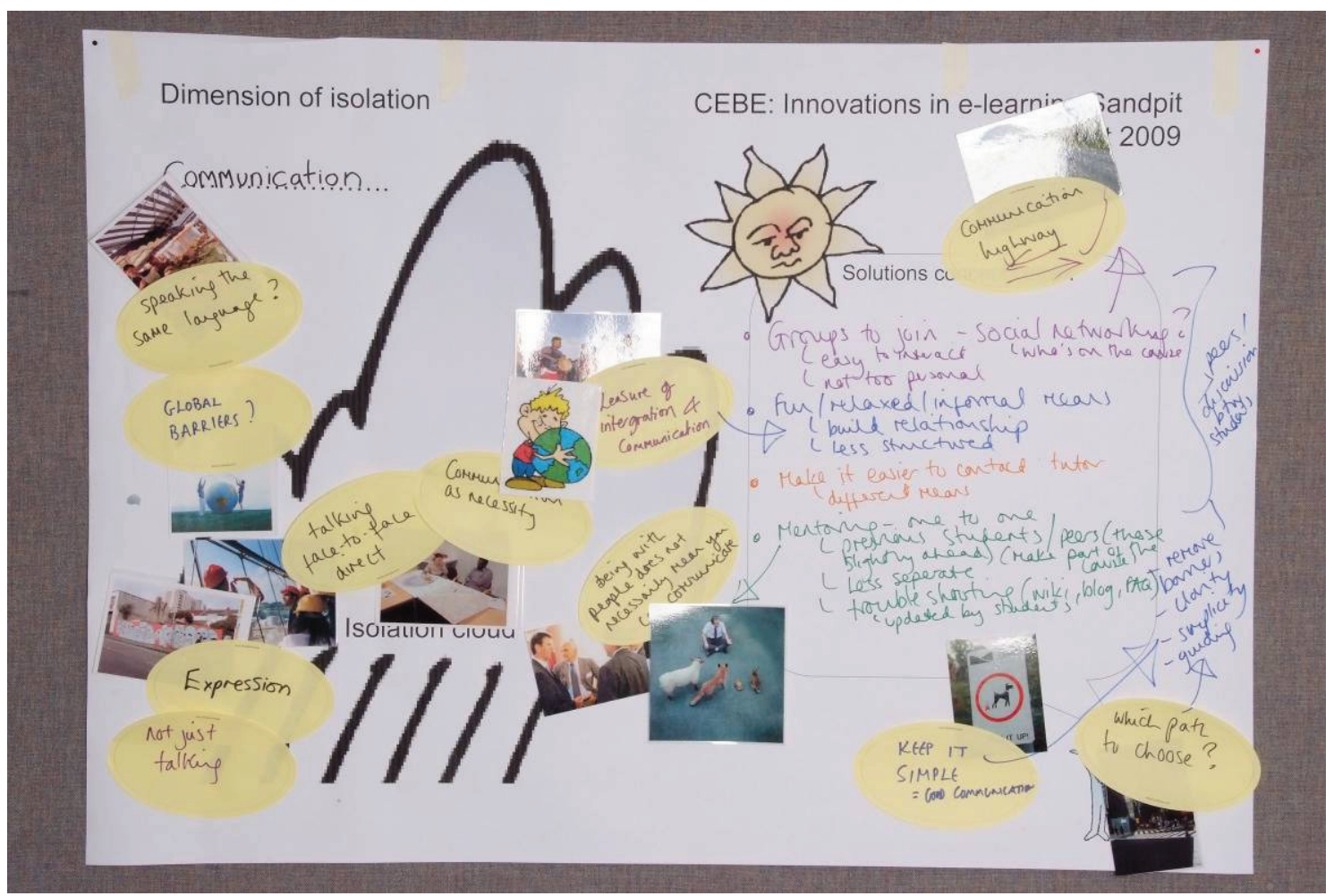

Figure 4 Detail of the first template used for capturing the isolation and conceptual solution image clouds

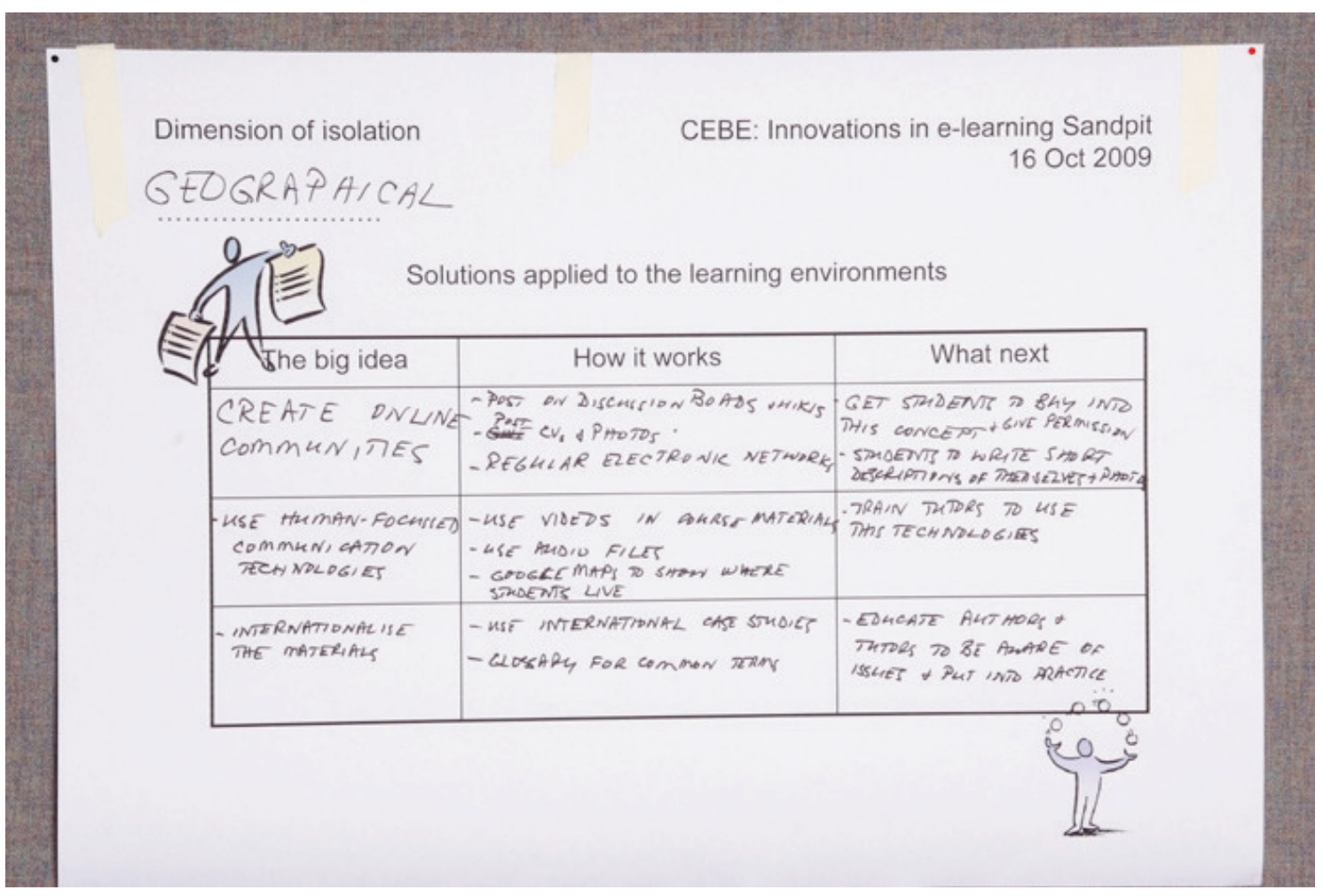

Figure 5 The second template used for capturing aspects of detailed solutions 
N. Croft, A. Dalton \& M. Grant: Overcoming Isolation in Distance Learning: Building a Learning Community through Time and Space

\section{Stage three}

The aim of the third stage of the research was to find out which of the 'big ideas' generated from the 'sandpit' workshop would potentially make a real difference to the student learning experience. Due to the geographically disparate nature of the students studying on distance learning courses, and the need to obtain and compare participant preferences, a questionnaire survey method of data collection was used. An instrument appropriate to the research was designed (Dillman, 2000) and administered online.

The survey obtained quantitative information to evaluate preferences and priorities regarding the 'big ideas' as potential solutions to overcome isolation in distance learning. It also requested qualitative information and offered respondents the opportunity to provide feedback to the ideas and explanation for their preferences. This permitted a feasibility assessment of the potential solutions. The questionnaire survey consisted of seven different sections, based on findings that had emerged from an analysis of the sandpit outcomes, exploring potential solutions to improve the student experience on distance learning courses: tutor contact; peer mentoring; online communities; student profiles; student location information; course material and delivery; and overall preferences (Appendix B).

The 19 interview participants plus an additional four who originally expressed an interest in the research were contacted by email by the research team and invited to complete the survey. A request was sent by one of the Student Advisors to a further 24 students on the MA Spatial Planning course. A total of 15 students fully completed the questionnaire, a response rate of $32 \%$. In presenting the findings we have identified the number of students raising particular issues.

Following this third stage of research, the feasibility of potential solutions to overcome the problems of distance learning was assessed. Using student feedback from the survey as well as from the interviews conducted during Stage One of the research, this enabled recommendations to be made regarding the future delivery of distance learning courses.

\section{Research Findings}

\section{Student experiences}

Reasons for choosing distance learning included flexibility, convenience, time and cost. Many respondents stated that learning by distance suited family, lifestyle and work commitments. The lack of availability of relevant courses near the home location of students was also a factor in deciding to enrol on a distance learning programme, as was the course content, suitability and uniqueness. Motivation for enrolling included improving skills, financial, professional progression, knowledge/CPD and personal satisfaction. 
N. Croft, A. Dalton \& M. Grant: Overcoming Isolation in Distance Learning: Building a Learning Community through Time and Space

Experiences of learning online and using Internet-based material varied according to previous experiences and familiarity with technology. Two students struggled to access material initially, but this improved over time. Eight others however found it easy to access material and felt that they were able to retrieve information that they would have problems finding without the Internet.

The ability to discuss ideas with fellow students was an aspect of learning that may be absent in online learning. One student stated that 'A lot of the more conceptual stuff is hard to learn or to get excited about when you're on your own; whereas talking about it is easy to argue and debate'. It was felt that verbal/written communication could not be a complete substitute for hearing a human voice or seeing another person. However, online discussions had helped one student's learning experience in the past by 'gaining information from people with different experiences, different perspectives'.

In terms of contact with the university, it was apparent that there was a divergence in terms of consistency of feedback that tutors were providing on their respective modules/topics. Variations were not only found in the quality of feedback but also in the speed of response. The importance and quality of support provided by the administrative team (Student Advisors) was found to be high. This is particularly important as the Student Advisor was often the main, or indeed only, point of contact.

Respondents generally did not feel physically connected to the university, with many having never visited the campus, even though one respondent lived close geographically.

\section{Challenges}

\section{Isolation and connectivity}

Psychological feelings of isolation may arise from the geographical separation and lack of contact with fellow students. Seven students mentioned the term isolation specifically and felt it was a problem for their learning, with one describing her learning as 'weird' and a 'solo mission'. However, not all students felt isolation to be a problem as they expected not to have face-to-face contact with the university or their peers, as they selected a programme which meant studying alone. Therefore, addressing negative feelings associated with isolation is a challenge, particularly as students have different needs and experiences.

\section{Tutor contact}

Maintaining appropriate levels and methods of contact between student and tutor is a major challenge for distance learning. Student experience of contact with tutors was hugely varied; seven felt that the tutor was there when required and that contact had been very good, whereas two others believed that the tutor was not available when they had needed someone to discuss an issue with. The need to 'build up the relationship' was apparent, as was knowing that someone was available if help was needed, particularly as help elsewhere may not be available: 'it was very difficult to 
N. Croft, A. Dalton \& M. Grant: Overcoming Isolation in Distance Learning: Building a Learning Community through Time and Space

actually discuss with anyone what I was doing'. All but one student believed more contact with the tutor would have improved their experience. Inconsistency in the quality ('it's varied hugely, depending on who my tutor has been') and brevity of feedback was raised. The lack of proactive tutor involvement was also thought to be a problem, raising a concern regarding level of service and student expectations. Speed of response was a further issue, with students commenting about out-of-office email acknowledgements not being switched on; the synchronicity of communication; frustration with lack of response; and immediacy of response ('you send an email and you could really do with a bit of a response straightaway... and sometimes it'll be a couple of days'). It remains a challenge to provide appropriate methods of contact when students have varying preferences and expectations: most respondents (17) preferred email although many (14) wanted to be able to telephone tutors and obtain an immediate response. Alternative technologies are available but it was felt that 'you need to get the basics right rather than upgrade the technology', for example, ensuring that emails are responded to promptly.

\section{Interaction with peers and colleagues}

Experience of students having contact with other students was extremely limited. Three respondents wanted to study alone but four others felt they were not able to interact with others due to distance/location; not knowing if others were doing the course; and not having the contact details to get in touch. Three respondents saw interaction with other students as being a 'social' activity which was not of interest to them, but two appreciated the help and assistance that such interaction could provide: 'when I was at university you could bounce ideas off each other and say, well how did you do that one?'. The lack of cohort contact was not necessarily viewed as an issue by three students. It was unclear from the interviews whether the respondents appreciated the potential benefits that discussions with fellow students can yield. Support from work colleagues during studies was varied.

Five students actively integrated the course into their work to tie their studies directly into their professional situations, which was encouraged by the reflective nature of online activities students are required to complete. For example specific tasks enabled students to investigate particular areas of their work that they were currently engaged in to compare and contrast their approach with practice around the UK. This was thought to provide extra motivation and purpose for the learning. The other students had not sought or were unable to obtain help from work colleagues illustrating that it is a challenge firstly to make students aware of potential benefits of interaction and collaboration, such as enriching breadth/depth of thought and testing out ideas, and secondly to facilitate this.

\section{Motivation and self-discipline}

Motivation poses a problem for distance learning students in particular as they do not have regular contact with other students, staff or the university to maintain momentum. 
N. Croft, A. Dalton \& M. Grant: Overcoming Isolation in Distance Learning: Building a Learning Community through Time and Space

Self discipline is clearly important, particularly when family and work commitments present challenges and perhaps unexpected pressures (such as caring for unwell children when assignments are due). Concerns were expressed regarding motivation and the computer-based nature of the course. Thirteen of the students cited meeting time deadlines, having targets to work towards, setting personal goals and remembering the purpose of undertaking the study (a qualification or as professional development) as being important motivational factors. It is clear that strategies and learning styles vary. One student preferred to undertake work in small segments but another favoured studying in large chunks to avoid approaching the study in a piecemeal or ad hoc manner.

\section{Material and delivery}

It is essential to ensure that the material has practical relevance and can encourage students to develop their understanding. Two interviewees believed that the course was too academic and not practically related to their work (too few case study examples). On the other hand, another felt that the course studied 'makes you think in different perspectives', a vital element of the concept of spatial planning. The datedness of material was raised as an issue by eight students, highlighting that whilst distance learning material can use the power of Internet search engines and recent sources, it can also date quickly as it is written at a point in time.

Personal preference and learning style represents a challenge for the format of delivery. Eight students wanted paper based material to 'offer people the opportunity to opt out of online study' and 'because I'm somebody who doesn't like working off the computer all the time'. On the other hand, nine others commented that there was too much paper involved, that postal delivery means there is 'no real ability for a proper dialogue' and that there are significant time delays if material is mailed. Therefore, there was no universal agreement over the most appropriate methods to deliver course material. One student felt that paying course fees, reading online material and then submitting a subsequent piece of work was not sufficient on its own to provide a good learning experience, citing that 'I felt more as a customer'. This highlights the need for wider aspects of learning that go beyond a pure money-for-qualifications transaction, to be embedded in the distance learning package. This requires the learning experience to be enriched.

\section{Student expectations}

The students who were interviewed had differing expectations as to university requirements and different experiences in the delivery of their courses. Uncertainty included: the amount of time to spend reading; the quantity of material to access; the quality/style of assignments; the opportunity to contact staff for guidance; and the opportunity to receive formative feedback. Receiving such feedback from students is an important element of developing solutions to overcome the challenges presented for distance learning. 
N. Croft, A. Dalton \& M. Grant: Overcoming Isolation in Distance Learning: Building a Learning Community through Time and Space

\section{Solutions}

\section{Improving tutor-student contact}

The research interviews and the 'sandpit' suggested potential solutions to improve tutor-student contact. Contact should be made easy, simple and reliable, improving on current contact. It is important to set out expectations of the student/tutor relationship (some form of service level agreement) and for assignments (including comparative material and past essays: 'it kind of gave me an idea of how they wanted it structured and it was really helpful.') at an early stage. Increasing frequency, quality, availability and timeliness of contact and feedback was seen as essential (for 'reassurance that they're heading in the right direction'). Providing the opportunity (voluntary) for face-toface contact by visiting the campus and/or meeting other students was a suggestion by some. The provision and use of support mechanisms needs to be a two-way process between staff and students: students need to be able to raise concerns if and when they arise, but tutors should actively use 'staging points' at which students are contacted concerning their progress. Increasing familiarity between student and tutor is an important goal that should be instigated at course commencement with a tutor welcome address and perhaps an online profile. Students should be provided with the option to opt-out of discussions to meet individual preferences and learning needs.

According to the questionnaire survey, improvements to student/tutor contact should be directed to the nature of the contact rather than the methods used. (Two thirds of questionnaire respondents were happy with the amount of contact they have with their tutors and all but two were happy with current methods available, although at the earlier stage of data collection fourteen believed that incorporating telephone discussions would be beneficial.) Frequent prompts/encouragement from tutors was seen as a proactive measure to make students feel like they were not studying alone, to help with motivation and to encourage a dialogue between tutor and student. This could be improved by the following: quicker response to queries; an initial welcome, outlining how the student-tutor relationship works (tutor availability, online diary, anticipated level of contact, expectations); notification/agreement of availability for contact (email, telephone); frequent encouragement/support emails (start, middle and end of modules); more detailed feedback; notification of absences (holiday, sick periods); acknowledgement of submissions and to provide opportunity to meet in person.

\section{E-mentoring}

Increasing peer support online was seen as an important method for overcoming feelings of isolation in distance learning programmes from the 'sandpit' session. Peer assisted learning (PAL) was proposed, where a mentor in the form of a peer would be assigned to new students, someone who had already had experience of the course. The purpose would be to ensure students had more informal contact with someone who could help and advise on a one-to-one basis. 
N. Croft, A. Dalton \& M. Grant: Overcoming Isolation in Distance Learning: Building a Learning Community through Time and Space

There was a mixed response to the idea of mentoring from the interview stage of the research, illustrating the different approaches to learning that students employ.

Thirteen respondents thought peer mentoring would be 'good' or 'useful', for encouragement, discussion and support. Those who did not wish to involve others in their studies expressed concerns such as 'I don't think l'd have the time for that, to be honest'. Those respondents who integrated the course material into their work place were keen to use work colleagues whilst two others sought family help, feeling that their family often fulfilled a mentoring role in respect of keeping them enthused and active with their studies.

Eight questionnaire respondents suggested they would like a mentor with seven stating that they would not. Some, particularly those on longer courses, would find it useful for encouragement, guidance, advice and support, particularly at the early stages. Eight would be prepared to be a mentor, but expressed concerns regarding time pressures and other commitments. It is noted that of the eight, three did not express a need to be mentored, as they were happy with their current level of support and guidance from tutors and work colleagues. However, three of the eight who would like a mentor were not prepared to be a mentor themselves due to time commitments or lack of confidence. The feasibility of mentoring is therefore questionable. If implemented, various factors would need to be considered, including: mentor training, guidelines, availability, knowledge, commitment, and matching mentors with mentees (similar experiences, courses and background etc).

\section{Creating online communities}

The idea of creating online communities of students to overcome the lack of direct contact with fellow students was suggested at the 'sandpit' workshop. Introducing and maintaining a format for online discussions, such as discussion boards and wikis was seen as a potential solution, to allow students to record and discuss experiences during and throughout their course. The idea of social networking was explored, suggesting the possibility of using Facebook style groups for communication and integration. It was felt that tutor facilitation and stimulation would be required to generate these discussions and ensure that they were used on a regular basis. The use of more humanised forms of discussion such as webcasts was proposed.

There was almost unanimous support for more student-student interaction from the interviewees to provide an 'online student resource where people can talk to each other'. Students were interested in 'seeing different points of view', discussing issues, exchanging information and creating 'colour added discussions', perhaps as a way of 'replicating the sort of discussion you have in, perhaps a tutorial seminar'. A couple of respondents mentioned that it would be useful to have a list of other students' e-mail addresses so that they could enter into a dialogue. Students had concerns about synchronicity of message board discussions, the longevity of the activity, requiring an opt-out option, having a cut off date and the convenience of where the link was located online. The majority (twelve) of interviewees were dismissive of the potential for using 
N. Croft, A. Dalton \& M. Grant: Overcoming Isolation in Distance Learning: Building a Learning Community through Time and Space

social networking sites citing: flexibility of study times; desire to study alone; needing to know people first; a dislike of new technology; and retaining distinction between social activity and academic work. Some students had used blogs and wikis previously, whereas others had not, although there was a general willingness from interviewees to engage with new approaches. Whilst one student thought that blogging would be useful they caveated this by noting the asynchronicity of the course. Concerns were expressed with the use of wikis: accuracy of content, manageability, use of unfamiliar technology, need for careful monitoring by tutors, and the time required for participation.

Twelve questionnaire respondents said they would like to be part of an online community, to discuss subjects or particular issues with fellow students online. It was noted that for this to be successful, there would need to be a number of people actively engaging and perhaps some outside facilitation. Ten respondents said they would read wikis, and eleven would actively contribute to them, as they would be useful for gaining up-to-date information, to expand particular topics and to make students feel part of a learning community. Issues of relevance and accuracy were raised, suggesting that if wikis were used they would have to either come with a disclaimer or would need to be assessed/monitored/quality assured for content by the tutor. Guidance would be required regarding the operation of a wiki. Time constraints and confidence in individual knowledge may prevent students from participating.

\section{Displaying student profiles}

In order to feel more connected and familiar with fellow students, the 'sandpit' workshop developed the idea of posting individual student profiles online at the enrolment stage. These profiles could include short descriptions of themselves, interests, skills, work experience and photos.

Two thirds of questionnaire respondents said they would read the profiles of other students and nine would post their own profile; the same number of respondents thought that this would be useful or potentially useful, some as a way of identifying peers they could meet with in person or to share/find people with similar interests and backgrounds. Most said they would look at other profiles through curiosity. Only a third believed seeing student profiles as not relevant or useful, that they were engaged on the course for a short while, or that they did not want information about themselves being made available to others. One respondent expressed concern that they might be prejudged based on the profile. Using student profiles therefore is a potentially useful way to build online communities, provided involvement was voluntary. If this was introduced, profiles could include information about: the course/topics, work experience, areas of expertise, academic and professional background. Aspects to be addressed by UWE would need to include: confidentiality, access, data protection/security and identity theft. 
N. Croft, A. Dalton \& M. Grant: Overcoming Isolation in Distance Learning: Building a Learning Community through Time and Space

\section{Mapping student locations}

In order for students to be aware of the locations of other students studying on distance learning programmes, an idea was proposed during the workshop of providing a map of student home locations. This would enable students to identify who was working on a module at one time, perhaps by applying a sign in when logging on to a module. This could take on an established format such as that of Google Maps.

Two thirds of questionnaire respondents would like to know where fellow students are located geographically and the same number would like other students to know where they are located geographically. This would be used purely out of interest/curiosity, to assess the potential for face-to-face meetings/networking with peers, to feel part of a community with others who are studying online and possibly to help those in remote settings when studying particular topics. One third of respondents did not see this information as relevant to their learning.

\section{Material format, delivery, content and knowledge development}

Participants in the 'sandpit' workshop felt that the concept of accreting material within the course over time to deepen the student learning experience had great potential. Student-generated content such as tips and experiences and useful material and web sites could be created. These 'hidden gems' (material developed by students and/or staff amongst the course material to be discovered, indicated though 'buried' markers in the learning path); and 'footprints' (student comments, advice and guidance added throughout the course materials, using the concept of accretive material to indicate that previous students had passed that way), could build-up and share the knowledge that would normally be exchanged during face-to-face meetings, lectures and tutorials. Recording student experiences and developing a stories archive were other potential ideas for generating content. Additions and changes to course material were suggested, including a glossary for common terms and more variety in the use of multimedia to supplement existing course material, such as audio and video files. Wikis could be a place where 'tutors could drop relevant bits and info for discussion, journals etcetera'. A common thread of the 'sandpit' session was the need to 'humanise' the course, as there is an absence of the first person in distance learning, with few explicit indicators of personality, personalisation or individuality.

Interviewees felt that accreted message boards linked to particular aspects of modules/topics could be useful. Particular concerns were expressed, including: a lack of spontaneity; the feeling that tutors could be checking up on students' engagement with the module and the need to ensure equal participation and engagement by others. Students felt video conferencing would not be a viable addition to the course, with issues of cost, synchronicity, availability, personal preferences, technological difficulties/availability, and the constraint of needing to be available at a predetermined time and location all cited. These factors mean that this is unlikely to be a particularly useful tool for distance learning in the particular context of the MA Spatial Planning. 
N. Croft, A. Dalton \& M. Grant: Overcoming Isolation in Distance Learning: Building a Learning Community through Time and Space

Almost all questionnaire respondents also said they would welcome tips/'hidden gems' placed by fellow students and the same number would contribute to posting these. It was felt that, if relevant, this would help future students negotiate the topics, share information and experiences, and to generate up-to-date content. This may be less useful for those studying on single modules/topics rather than longer courses. One felt that this would not reduce the sense of isolation from the university and tutors. A positive response was received by over two thirds of questionnaire respondents for such potential additions to the course. Only one student said she would not be happy to post additional material for future students, all others thought that they would if they had relevant material. The overall opinion was that any additional help received would be beneficial, particularly 'real world' examples perhaps in alternative formats to the typical course content, but with a need to 'keep it simple'.

\section{Overall student preferences}

In terms of preference for improvements to distance learning programmes, four potential solutions were ranked considerably higher than other potential areas of improvement in the questionnaire survey:

- Improved tutor contact

- Discussing experiences and tips with peers

- Tips and comments posted by previous students

- Material and content posted by previous students

Knowing about who and where fellow students are, being mentored by a peer and receiving alternative delivery methods were lower priorities.

\section{Conclusions and Recommendations}

\section{Conclusions}

The student learning experience on a non-campus based programme, where there is no course cohort, can be enriched through reducing the potential for isolation. This research has identified that isolation was a problem experienced by students, with direct and indirect influences on their learning experience. Further barriers and challenges were identified relating to the difficulty of delivering and maintaining distance learning courses. The need to create a form of learning community, where peer contact is enabled and students are encouraged to share their work/thoughts, was identified as an overarching theme in the research. The importance of improving tutorstudent communication was identified as a second theme, tutors should also be seen as part of a potential learning community. Various measures exist which could be used to overcome the challenges and to create an online community, even in an asynchronous environment; these measures can address issues of isolation either directly or indirectly. A particular concern with the asynchronous MA Spatial Planning is the difficulty of introducing online communication with participants potentially being widely separated in time (students studying the same topic may be separated by a 
N. Croft, A. Dalton \& M. Grant: Overcoming Isolation in Distance Learning: Building a Learning Community through Time and Space

matter of months), geographically and by professional sector. The feasibility and potential to use specific, creatively generated, approaches was assessed, and this informs the recommendations that the research proposes, outlined in the following section.

An important message from the research is the need to 'get the basics right', by tightening up the current course and its processes, making sure that the simple things are done properly, such as timely e-mails from tutors and encouragement/feedback to an agreed standard. Needing a human dimension to the course is an apparent need with distance learning, apparent with suggestions for student and staff profiles, material captured from users, more contact, tighter response timing and online communities. As a first step it was felt that course authors and tutors need to be made aware of this overarching aspect of isolation, the various dimensions of isolation, and to put into place a variety of practices to 'humanise' the online distance learning courses, such as photographs and personal biographies of staff. The relevant question for the MA and for distance learning generally is how to take forward the agenda with tutors on these programmes, in order that appropriate action can be taken within a teaching environment where tutors themselves can also feel isolated from the students.

\section{Recommendations}

The next stage in this action orientated research is to feed back research findings to all tutors, in order to obtain their comments on feasibility of recommendations, discuss their ability to participate, and to devise a plan of action for short and long term improvements which could help overcome isolation in the online learning environment. Specific actions have been identified for distance learning courses at UWE that will help to enrich the student experience and reduce feelings of isolation. These include:

\section{Student-tutor communication and presence}

- Humanise the course by including staff profiles with photos alongside relevant modules and topics

- Providing service level agreements so that students know when they can expect a tutor response and ensuring quicker tutor response to queries

- Make online calendars of tutor availability, ensuring tutors notify students of any periods of absence due to holidays, sick leave etc.

- Introduce student welcome emails from module/topic tutors, offering a friendly welcome with guidelines for expectations of contact, response times, feedback and information about the student/tutor relationship

- Encourage more detailed feedback by tutors and send acknowledgement of submissions

- Designate 'staging points' for tutors to email their students, to encourage their studies and to check on progress

- Offer students the opportunity to visit the university and meet the tutor in person 
N. Croft, A. Dalton \& M. Grant: Overcoming Isolation in Distance Learning: Building a Learning Community through Time and Space

\section{Student-student communication and presence}

- Develop ideas around student generated accretive content to provide tips, reviews and commentary as 'footprints' and/or 'hidden gems'

- Provide more case studies to illustrate course materials and relate them to real world practice

- Provide examples of previous student work to demonstrate the UWE expectations with regard to the required standard for assessments

- Generate a social presence through encouraging students to contact each other to discuss material and develop critical thinking (noting that communication should allow for social and work-orientated dialogue)

- Introduce a mechanism (for example a wiki) to provide students with their peers' thoughts on course material, to include: succinct guidelines/information, a clear outline of expectations, a disclaimer, use of a moderator, and integration into assessment

- Provide a geographic information feature which will broadly indicate the location of students on the course, facilitating mediated contact if required

Having discussed and refined these recommendations with the academic and student support team, the implementation phase will commence with discussions with the IT technical development service (some of whom were at the creative workshop).

Comparing the findings of this research with those in the wider literature, it would appear that many of the issues raised are common across subjects, professions and countries. The recommendations are pedagogically led rather than subject orientated and therefore whilst specific recommendations are made for UWE distance learning courses, and in particular for asynchronous non-cohort situations, these are applicable to other courses in higher education due to the similarity of issues experienced with distance learning generally.

The work has benefits to the wider built environment community in that the issues raised are generic across professions within the built environment. Whilst the individual contexts, courses and procedures will vary, and some of these mechanisms may already be employed, the conceptual ideas generated for overcoming student isolation have pertinence to others preparing and delivering distance learning material.

\section{Considerations, limitations and implications for the future}

Many of the solutions provided are conceptual and therefore the true feasibility and impact will not be known until they are employed. The implementation phase of this research will need to include user evaluation and refinement of any adopted solutions. In addition, it is noted that the sum of solutions may be greater than their individual components, a tipping point is hoped for whereby implementation of a number of key recommendations will transform the character of the course from an austere content delivery platform to an interactive and human faced environment. 
N. Croft, A. Dalton \& M. Grant: Overcoming Isolation in Distance Learning: Building a Learning Community through Time and Space

The empirical findings of this research were obtained from a small sample of students studying on distance learning modules at UWE. Data protection legislation limited the opportunity for contacting students and therefore influenced the sample size and response rates. This has provided a diverse range of opinions with in-depth qualitative information, its objective was never to be representative of online learners generally.

Non-cohort courses are currently rare, but distance learning will continue to be used to deliver educational programmes especially in a context offering 'roll-on roll-off' courses and lifelong learning. The challenges and barriers to learning will remain and methods will continue to be required to overcome these and enhance the student experience for this type of delivery. For UWE, the crucial next stage is to consult with tutors and work together to apply solutions. We will be undertaking further research to assess the impact of the solutions applied. Sharing good practice examples from higher education courses on this pedagogical issue will be a vital component to delivering and developing online learning in the future. 
N. Croft, A. Dalton \& M. Grant: Overcoming Isolation in Distance Learning: Building a Learning Community through Time and Space

\section{References}

Academy for Sustainable Communities. (2007). Mind the skills gap: The skills we need for sustainable communities [online]. Leeds: Academy for Sustainable Communities. URL: http://www.hcaacademy.co.uk/whatwedo/mind-the-skills-gap-research [Accessed 7th January 2010].

Alexander, S. (2001). E-learning developments and experiences. Education and Training, 43 (4/5), 240-248.

Asset Skills. (2006). Sector Skills agreement stage three UK wide report, November 2006. Northampton: Sector Skills Council.

Audit Commission. (2006). The planning system - matching expectations with capacity. London: Audit Commission.

Barrett, E. \& Lally, V. (2000). Meeting new challenges in educational research training: The signposts for educational research CD-ROM. British Educational Research Journal, 26 (2), 271-290.

Bergman, M. (Ed.). (2008). Advances in mixed methods research: Theories and applications. London: SAGE Publications Ltd.

Bernard, R. M., Rojo de Rubalcava, B. \& St-Pierre, D. (2000). Collaborative online distance learning: Issues for future practice and research. Distance Education, 21 (2), 260-277.

Bonwell, C. \& Eison, J. (1991). Active learning: Creating excitement in the classroom. AEHE-ERIC Higher Education Report No. 1. Washington, D.C.: Jossey-Bass.

Boyatzis, R. E. (1998). Transforming qualitative information: Thematic analysis and code development. London: Sage.

Bryan, T. (2003). On-line topic based flexible learning. In: Proceedings of the ITC EDU 2003 2nd International Workshop on Construction Information Technology in Education. Carlton Madeira Hotel, Funchal, Madeira Island, Portugal, July 26-30.

Bryan, T., Graham, C. \& Porritt, N. (2003). A web-based learning environment for lowtech students, authors and administrators. In Proceedings of the ALT-C: 2003 Communities of Practice Conference by the Association for Learning Technology. University of Sheffield, September 8-10. Sheffield, University of Sheffield.

Carswell, L., Thomas, P., Petre, M., Price, B. \& Richards, M. (2000). Distance education via the Internet: The student experience. British Journal of Educational Technology, 31 (1), 29-46.

Chee, Y. S. (2002). Refocusing learning on pedagogy in a connected world. On the Horizon - The Strategic Planning Resource for Education Professionals, 10 (4), 7-13. 
N. Croft, A. Dalton \& M. Grant: Overcoming Isolation in Distance Learning: Building a Learning Community through Time and Space

Cleveland, P. L. \& Bailey, E. K. (1994). Organizing for distance education. In: Proceedings of the Twenty-Seventh Annual Hawaii International Conference on System Sciences 4. Los Alamos, CA. pp.134-141.

Compeau, D. \& Higgins, C. (1995). Computer self-efficacy: Development of a measure and initial test. MIS Quarterly, 19 (2), 189-211.

Connolly, M., Jones, N. \& O'Shea, J. (2005). Quality assurance and e-learning: Reflections from the front line. Quality in Higher Education, 11 (1), 59-67.

Croft, N. (2007). Recruitment problems: Is the cupboard bare or do local authorities just need to try new ways to stock the larder? Branchout No.134. Royal Town Planning Institute South West regional magazine, Winter 2007, p. 6.

Dickey, M. D. (2004). The impact of web-logs (blogs) on student perceptions of isolation and alienation in a web based distance-learning environment. Open Learning, 19 (3), 279-291.

Dillman, D. A. (2000). Mail and Internet surveys: The tailored design method. 2nd ed. New York: John Wiley \& Sons, Inc.

Directgov. (2009). Getting into higher education as a mature student [online]. URL: http://www.direct.gov.uk/en/EducationAndLearning/UniversityAndHigherEducation/Why GoToUniversityOrCollege/DG 4017026 [Accessed 6th January 2010].

Dron, J. (2006). The way of the termite: A theoretically grounded approach to the design of e-learning environments. International Journal of Web Based Communities, 2 (1), 3-16.

Eastmond, D. \& Ziegahn, L. (1995). Instructional design for the online classroom. In: Berge, Z. L. \& Collins, M. P. (Eds.). Computer mediated communication and the online classroom. Cresskill, N.J.: Hampton Press, Vol 3, pp. 59-80.

Fry, H., Ketteridge, S. \& Marshall, S. (2003). A handbook for teaching and learning in higher education - enhancing academic practice. London: Kogon Page.

Gammie, E., Gammie, B. \& Duncan, F. (2002). Operating a distance learning module within an undergraduate work placement: Some reflections. Education and Training, 44 (1) $11-22$.

Garnet, D. (2005). Flexible learning in context: An introduction to business planning for housing [online]. Bristol: University of the West of England. URL:

http://www.innovationintoaction.org/downloads/025UWEFlicFlexibleLearningInContext. pdf [Accessed 15th January 2010].

Garrison, D. R., Anderson, T. \& Archer, W. (2000). Critical inquiry in a text-based environment: Computer conferencing in higher education. The Internet and Higher Education, 2 (2-3), 87-105. 
N. Croft, A. Dalton \& M. Grant: Overcoming Isolation in Distance Learning: Building a Learning Community through Time and Space

Gibson, J. W., Tesone, D. V. \& Blackwell, C. W. (2001). The journey to cyberspace: Reflections from three online business professors. SAM Advanced Management Journal, 66 (1), 30-34.

Glaser, B. G. (1992). Basics of grounded theory analysis: Emergence vs. forcing. Mill Valley, California: Sociology Press.

Gulati, S. (2008). Compulsory participation in online discussions: Is this constructivism or normalisation of learning? Innovations in Education and Teaching International, 45 (2), 183-192.

Hamid, A. A. (2002). e-Learning is it the "e" or the learning that matters? Internet and Higher Education, 4 (3-4), 311-316.

Hartley, S., Gill, D., Walters, K., Bryant, P. \& Carter, F. (2001). Twelve tips for potential distance learners. Medical Teacher, 23 (1), 12-15.

Hughes, M. \& Daykin, N. (2002). Towards constructivism: Investigating students' perceptions and learning as a result of using an online environment. Innovations in Education and Teaching International, 39 (3), 217-223.

Ipsos MORI. (2007). Student expectations study: Key findings from online research and discussion evenings held in June 2007 for the Joint Information Systems Committee [online]. URL:

http://www.jisc.ac.uk/media/documents/publications/studentexpectations.pdf [Accessed $7^{\text {th }}$ January 2010].

Jones, M. (2006). Voices across the digital divide. Interactions, 13 (3), 16-17.

Kolb, D. A. (1984). Experiential learning: Experience as the source of learning and development. New Jersey: Prentice-Hall.

Lake, D. (1999). Reducing isolation for distance students: An on-line initiative. Open Learning, 14 (3), 14-23.

Liu, S. (2008). Student interaction experiences in distance learning courses: A phenomenological study. Online Journal of Distance Learning Administration [online], 11 (1) URL: http://www.westga.edu/ distance/ojdla/spring111/Liu111.html [Accessed 15th October 2009].

Liu, X., Magjuka, R. J., \& Lee, S. (2006). An empirical examination of sense of community and its effect on students' satisfaction, perceived learning outcome, and learning engagement in online MBA courses. International Journal of Instructional Technology and Distance Learning, 3 (7), 1-15.

Lorenzetti, J. P. (2005). Lessons learned about student issues in on-line learning. Distance Education Report, 9 (6), 3-4.

Lynch, M. (2004). Learning on-line - a guide to success in the virtual classroom. London: RoutledgeFalmer. 
N. Croft, A. Dalton \& M. Grant: Overcoming Isolation in Distance Learning: Building a Learning Community through Time and Space

Mason, R. \& Bacsich, P. (1998). Embedding computer conferencing into university teaching. Computers and Education, 30 (3-4), 249-258.

Miller, L. C., Devaney, S. W., Kelly, G. L. \& Kuehn, A. F. (2008). E-mentoring in public health nursing practice. The Journal of Continuing Education in Nursing, September 2008, 39 (9), 394-399.

Nipper, S. (1989). Third generation distance learning and computer conferencing. In: Mason, R. \& Kaye, A. (Eds.). Mindweave: Communication, computers and distance education. Oxford: Pergamon, pp. 63-73.

Park, C. (2008). The taught postgraduate student experience: Overview of a Higher Education Academy survey. York: The Higher Education Academy.

Quilter, S. \& Weber, R. K. (2004). Quality assurance for on-line teaching in higher education: Considering and identifying best practice for e-learning. International Journal of E-Learning, 3 (2), 64-73.

Robson, C. (2002). Real world research: A resource for social scientists and practitioner-researchers. 2nd ed. Oxford: Blackwell.

Rogers, J. (2001). Adults learning. 4th ed. Buckingham: OU Press.

Rovai, A. P. (2001). Building classroom community at a distance: A case study. Educational Technology Research and Development Journal, 49 (4), 33-48.

Rovai, A., Ponton, M., Wighting, M. \& Baker, J. (2007). A comparative analysis of student motivation in traditional classroom and e-learning courses. International Journal on E-Learning, 6 (3), 413-432.

Royal Town Planning Institute. (2005). A survey of discipline knowledge and generic skills of RTPI corporate members. Membership Education and Lifelong Learning Department. 3 November 2005. London: RTPI.

Royal Town Planning Institute. (2007). CPD frequently asked questions [online]. London: RTPI. URL: http://www.rtpi.org.uk/item/290 [Accessed 15th October 2008].

Rust, C. (2002). The impact of assessment on student learning - how can the research literature practically help to inform the development of departmental assessment strategies and learner-centred assessment practices? Active Learning in Higher Education, 3 (2), 145-158.

Salmon, G. (2000). E-moderating: The key to teaching and on-line learning. London: Kogan Page.

So, H. \& Brush, T. (2008). Student perceptions of collaborative learning, social presence and satisfaction in a blended learning environment: Relationships and critical factors. Computers and Education, 51 (1), 318-336. 
N. Croft, A. Dalton \& M. Grant: Overcoming Isolation in Distance Learning: Building a Learning Community through Time and Space

Stacey, E. (1999). Collaborative learning in an online environment. Journal of Distance Education [online], 14 (2), 14-33. URL:

http://www.jofde.ca/index.php/jde/article/view/154/379 [Accessed 7th January 2010].

Stodel, E. J., Thompson, T. L. \& MacDonald, C. J. (2006). Learners' perspectives on what is missing from online learning: Interpretations through the community of inquiry framework. The International Review of Research in Open and Distance Learning, 7 (3), 1-24.

Sturges, J. E. \& Hanrahan, K. J. (2004). Comparing telephone and face-to-face qualitative interviewing: A research note. Qualitative Research, 4 (1), 107-118.

Talbot, J. (2007). Delivering distance education for modern government: the F4Gov programme. Journal of Education and Training, 49 (3), 250-60.

Thomas, E. J. (1995). Developing continuing education and training in European universities. Journal of European Industrial Training, 19 (4), 11-15.

Thomas, M. J. W. (2002). Learning within incoherent structures: The space of online discussion forums. Journal of Computer Assisted Learning, 18 (3), 351-366.

University of the West of England. (2009). Department of Planning and Architecture: Professional development [online]. URL: http://www.bne.uwe.ac.uk/pa/profDev.asp [Accessed 7th January 2010].

Venter, K. (2003). Coping with isolation: The role of culture in adult distance learners' use of surrogates. Open Learning, 18 (3), 271-287.

Vygotsky, L. S. (1978). Mind in society: The development of higher psychological processes. Cole, M., John-Steiner, V., Scribner S., \& Souberman, E. (Eds.).

Cambridge: Cambridge University Press.

Wall, J., Ahmed, V. \& Smit, D. (2006). Issues in addressing the lifelong learning needs of construction professionals using technology facilitated learning - Experiences from an Irish blended learning initiative. In: Proceedings CIBW89 - International Conference on Building Education and Research, 1 (2), 57-69.

Webster, J. \& Hackley, P. (1997). Teaching effectiveness in technology-mediated distance learning. Academy of Management Journal, 40 (6), 1282-1309.

Wegner, S. B., Holloway, K. C. \& Garton, E. M. (1999). The effects of internet-based instruction on student learning. Journal of Asynchronous Learning Networks, 3 (2), 98106.

Weller, M. (2002). Delivering learning on the net: The why what and how of on-line education. London: Routledge Falmer.

Whiting, M. J., Liu, J., \& Rovai, A. P. (2008). Distinguishing sense of community and motivation characteristics between online and traditional college students. The Quarterly Review of Distance Education, 9 (3), 285-295. 
N. Croft, A. Dalton \& M. Grant: Overcoming Isolation in Distance Learning: Building a Learning Community through Time and Space

Willis, B. (1994). Distance education: Strategies and tools. Englewood Cliffs, NJ: Educational Technology. 
N. Croft, A. Dalton \& M. Grant: Overcoming Isolation in Distance Learning: Building a Learning Community through Time and Space

\section{Appendix A}

\section{Interviewer guidance sheet}

Opening protocol

Purpose of research, format and length of interview, questions raised

\section{A The course/programme/topic}

A1 Course enrolled on

A2 Purpose of study

B Distance learning experience

B1 Previous experience of studying at university

B2 Reasons for choosing distance learning

B3 Initial feelings about starting on the programme/course/module/topic

B4 Factors contributing to any initial concerns

B5 Aspect/s of the programme/course/module/topic particularly liked

B6 Aspect/s of the programme/course/module/topic particularly disliked

B7 Difficulties with any modules/topics

B8 Motivation during your studies

B9 Connectedness with the University and other students

B10 Expectations of the time and resources required

B11 Support from university/students/work colleagues

B12 Student interaction and contact with fellow students

B13 Involved in structured on-line discussion

B14 Positive and negative experiences

B15 The most important thing that could be done to improve your experience

C Improving the student experience

C1 Forms of communication familiar with that may be useful to distance learners

C2 Methods to improve the student experience

D Employment details

D1 Employer name/location during study

D2 Employer's business

D3 Number of related professionals in the organisation

D4 Student's role/position within the organisation

D5 Length of related professional employment at time of enrolling 
N. Croft, A. Dalton \& M. Grant: Overcoming Isolation in Distance Learning: Building a Learning Community through Time and Space

\section{Appendix B}

\section{Research questionnaire}

Page 1. Welcome

Introduction to the project and with contact details of the research team

\section{Page 2. Tutor contact}

1. Are you happy with the amount of contact you have with your tutor?

2. For you, what makes good quality tutor contact? Please briefly describe below:

3. If you are unhappy with current amount or quality of tutor contact, which of the following would help? Please choose all that apply...

4. Which methods do you use to communicate with your tutor?

5. Are you happy with the current methods available to contact your tutor?

6. Are there any other ways we could improve the student/tutor relationship?

\section{Page 3. Peer mentoring}

7. Would you like to have a mentor?

8. Would you be prepared to be a mentor to a new student?

9. What factors should we consider if we use mentoring?

\section{Page 4. Online communities}

10. Would you like to feel part of an online community and be able to communicate with other students?

11. Would you read wikis created by your fellow students?

12. Would you contribute information to wikis for fellow students to use?

13. Do you have any further thoughts regarding creating 'online communities' for students studying via distance learning?

\section{Page 5. Student profiles}

14. How useful would it be to be able to see profiles of other students?

15. Would you read the profiles of other students?

16. Would you be prepared to put your profile online?

17. What would we need to consider to provide student profiles?

\section{Page 6. Student location information}

18. Would you like to know where other students are located geographically?

19. Would you like other students to know your broad geographic location?

20. Would you like the facility to be put in contact with the students who are closest to you geographically? 
N. Croft, A. Dalton \& M. Grant: Overcoming Isolation in Distance Learning: Building a Learning Community through Time and Space

\section{Page 7. Course material and delivery}

21. Would you welcome these tips or 'nuggets' posted by students?

22. Would you post your own tips and advice to help future students?

23. We could use other methods and material on distance learning courses. Please indicate if you would welcome the use of the following...

24. Would you be prepared to post additional material (for example, articles, web sites, glossary of terms, audio files or other resources), for future students?

25. Do you have any further thoughts regarding the implementation of alternative methods and material?

\section{Page 8. Your preferences}

26. From the following list, what would improve your experiences on UWE distance learning courses the most? Please choose your top 4 from the list below, entering rank ' 1 ' for the most important through to ' 4 '

27. Is there anything, not covered in the above list that we could do to improve distance learning at UWE?

28. Please indicate which programme title you are currently studying modules/topics on

\section{Page 9. Thank you}


N. Croft, A. Dalton \& M. Grant: Overcoming Isolation in Distance Learning: Building a Learning Community through Time and Space

\section{Improving distance learning experiences at UWE}

\section{Online communities}

We would like to find out more about your feelings towards being part of an 'online community'. An 'online community' would facilitate interaction and information sharing between students on distance learning courses.

Communication is 'virtual' for online communities. Exchanges are often carried out using discussion forums and threads (messages), for participants to omment on particular topics. The term 'Social networking' is sometimes used to describe the building of online communities of people who share interests and/or activities.

At UWE, we use discussion threads as part of our online 'Blackboard' sy stem:

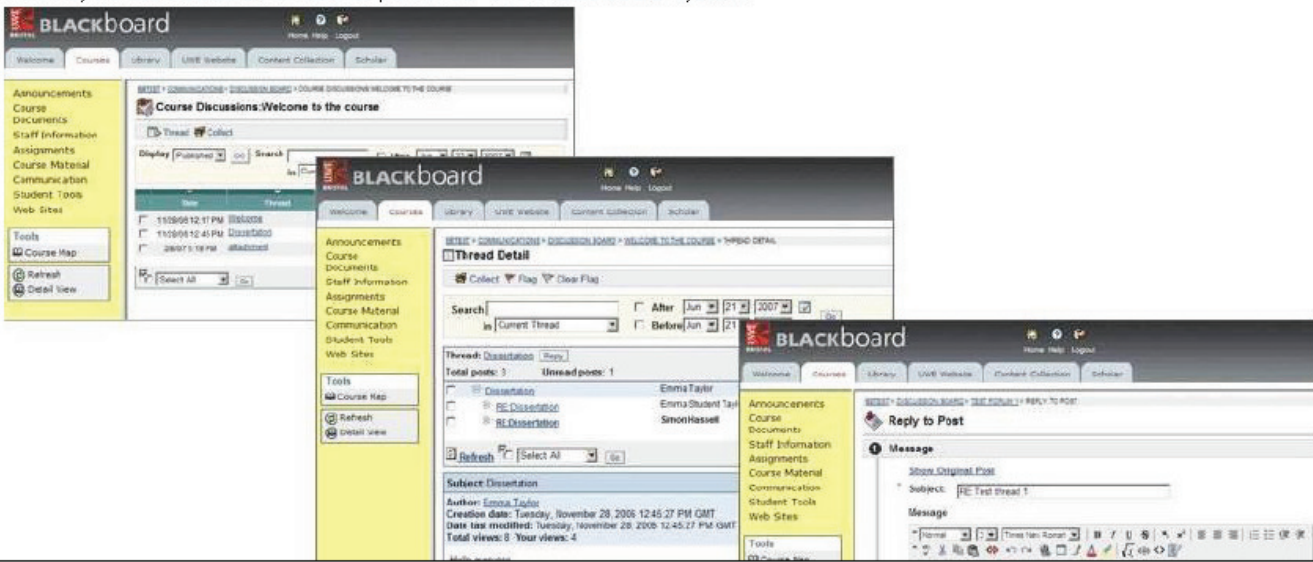

A section introducing the concept of an 'online community'

\section{Improving distance learning experiences at UWE}

23. We could use other methods and material on distance learning courses. Please indicate if you would you wel come the use of the following:

Additional material from previous students, such as

Yes, I would welcome this

0

articles and websites, inserted into the course material

A glossary of common terms

UWE created video clips for specific topics

Links to additional third party multimedia (audio, video

etc)

Do you have any other ideas or comments?

24. Would you be prepared to post additional material (for example, articles, web sites, glossary of terms, audio files or other resources), for future students?

Yres

No

Please explain your answer

$\Delta$

$\nabla$

A section asking about potential improvements to methods and material 